\title{
Cognitive Flexibility, Procrastination, and Need for Closure Predict Online Self-Directed Learning Among Pakistani Virtual University Students
}

\author{
Itbar Khan \\ Assistant Professor \\ University of Malakand, Pakistan \\ itbarkhan@uom.edu.pk \\ Marlene Schommer-Aikins \\ Wichita State University, KS, USA \\ marloschommeraikins@gmail.com \\ Nazia Saeed \\ $\mathrm{PhD}$ Scholar, \\ Department of Education, University of Malakand \\ ilikvm111@gmail.com
}

\begin{abstract}
This study investigated the relationship between students' self-directed online learning and their everyday psychological factors often associated with learning in general.Total 140 Virtual University students in Pakistan completed measures of online self-directed learning and psychological factors, including cognitive flexibility, procrastination, and need for closure. Regression analyses indicated that the less students procrastinate in general, the more students embraced cognitive flexibility, and the less they impulsively sought quick solutions, the more likely they reported effective online self-directed learning. In contrast, younger students, had a need for quick answers, procrastinate in general, and who embraced cognitive flexibility, were more likely to report ineffective online self-directed learning. The results suggest that students may be given training on how to avoid procrastination. Students need for closure can be eased by quizzes throughout the semester and students may be taught alternatives for encouraging cognitive flexibility.
\end{abstract}

Keywords: Online self-directed learning; Procrastination; Need for Closure; Cognitive Flexibility

\section{Introduction}

E-learning is becoming an essential part of academia all around the world and this integration has reshaped the process of teaching and learning. The expansion of e-learning programs and e-content development has provided new opportunities to educators to extend learning from the four walls of traditional schools to homes of people all over the world (Sawahel, 2013). The driving forces behind e-learning are the changing demographics of learners, changed condition for the transmission of knowledge and immense innovation in technology (Concannon, Flynn \& Campbell, 2005).

Pakistan being a member of the committee of nations is striving at its level to introduce elearning in higher education and slowly and gradually developing system for e-learning in the country. Pakistan wants to increase literacy rate and rate of admission in higher education. ELearning offer slow-cost education and it may encourage higher education in rural areas (Jumani \& Khan, 2009; Shah\& Attiq, 2017). Abidi, Pasha, \& Ali (2016) posit that a large number of people 
are already learning through Massive Open online Courses (MOOCs) from the United States of America (USA) and United Kingdom (UK) and these programs are liked because these are inexpensive, high quality, and they serve without any discrimination of rural and urban areas. They further say MOOCs may really solve problems of learners in Pakistan if the infrastructure is improved and MOOCs are launched in regional languages. Moreover, they add to the lists of benefits by mentioning that e-learning from quality universities adds to the confidence of learners and that too at a very low cost. They recommend that computer skills may be taught in low income and middle-income countries. Farid, Ahmad, Niaz, Arif, Shamshirband, \& Khattak, (2015) while investigating the impact of critical issues which impact e-learning in Pakistan posit that education can benefit from e-learning when issues like, developing learning outcomes in local languages, issues of low bandwidth, e-instructional designers, lack of implementation process, frequent power disruptions are resolved.

Pakistan took a major step towards e-learning by establishing a full-fledged Virtual University of Pakistan in 2002 which offers all courses online through its 195 regional centers all over the country (Federal Virtual University,2019). Pakistan also established the National ICT R\&D Fund for ICT-based learning and training in 2007 and developed ICT in Education Master Plan in 2007 wherein strategies have been given for the integration of ICT in education, improvement of students' learning, and developing capacities at different level. Moreover, The Higher Education Commission (HEC) sent 1700 scholars for higher education from 2013 - 2018 under faculty development program, digital library was provided to enable the learners to get access to thousands of books and journals (Higher Education, 2019). A large scale national Digital Skills (Digi Skills) Training Program has been launched for training one million of youth, freelancers, including women to enable them to work in the digital world. This project is being executed by the Virtual University of Pakistan (Ministry of Information, Technology and Telecom, Pakistan, 2019). Similarly, Allama Iqbal Open University (AIOU) of Pakistan has also started movement towards e-learning. In this project a center for instructional design has been established at AIOU for developing localized Learning Objects (Los) to assist local students. The "ICT in Education Master Plan- 2007' defines the strategies, focusing ICT for improving students' learning, expanding educational opportunities, and developing capacity at all levels. E-Learning stream of Allama Iqbal Open-University (Allama Iqbal Open University, Pakistan, 2019) COMSAT in Pakistan has also established Virtual Campus of COMSAT (COMSAT University Virtual Campus Islamabad,2019). Some other universities also launched online programs, for example, Agha Khan University Karachi. Moreover, Agha Khan University (AKU) was the first in Pakistan to launch three-week long MOOCs in 2014 on Bioinformatics of Drug Design. AKU added another course from the same platform in the year 2016. The organizers highlighted many factors in the context of Pakistani society for launching successful MOOC programs. First, faculties need to leave their comfort zone and review their approach in light of global context. Second, the course design must be astutely done as course must be learner friendly with technological factor considerations (Abidi, Pasha, Moran \&Ali, 2017).

In Pakistan e-learning is accepted as an alternative to formal education system. A large number of students are seeking admissions in Virtual University (VU) and Allama Iqbal Open University Islamabad (AIOU) because of their flexibility, national integration, and opportunities for higher education, uniform curricula and equal opportunity for all. The speed towards e-learning is slow because there are some challenges which e-learning faces in Pakistan, for instance, electricity failure, lack of availability and interruptions in internet, social isolation, time management, unfamiliarity with IT equipment and fatigue (Hussain, 2007; Hussain, 2012; Iqbal 
\& Ahmad, 2010; Jawaid, Kamran, Khan,\& Khalique, 2013; Khan \& Jumani, 2012).Noreen \&Hafeez (2016), while investigating technical challenges of digital learning from AIOU and VU, found that the academicians do not have enough knowledge about the use of ICT in distance learning, learners do not have access to technology, quality of learning material is low and there is lack of ICT professionals who are expert in e-learning. Qureshi, Ilyas, Yasmin, and Whitty (2012) investigated the challenges faced by private universities in the implementation of elearning. They found that electricity failure and English language proficiency were the main hurdles in the implementation. There is the need of systematic approach to technology use in education.

The foregoing review about e-learning in Pakistan shows that there are many benefits of elearning in Pakistan, if certain infrastructural and expertise issues are solved, then e-learning may prove very fruitful in Pakistan as well like other countries of the world. Many physical challenges have been investigated but there may be few studies which have investigated the psychological constructs of learners which would help in success, quality of learning and completion of learning through online MOOCs. Beside physical and technical facilities, there are other factors which also contribute to the success of online learning, as Albelbisi (2019) asserts that positive attitude towards MOOC contributes to the success of online learning. In the same vein, Piscitelli (2015) maintain that future universities need epistemological, discursive and ideological changes more than technical facilities. Similarly, cognitive flexibility, need for closure and procrastination are also influencing the success of learning through MOOCs.

Authors (2018) investigated the effect of cognitive flexibility, need for closure and procrastination among university students in USA and found that students with higher cognitive flexibility scores were better at exploring online sources, engaging with peers and instructors online, and monitoring the success of their learning. Students with high procrastination scores were less proficient in time management for online courses. Students with a strong need for closure were less proficient in managing their stress in online courses.

In Pakistan the effect of these psychological factors has not been investigated in online situation for learning. The study would further the findings of study conducted by Authors (2018) and find out a new aspect which plays an important role in the success of online learning. The current study investigates the effect of procrastination, need for closure and cognitive flexibility in Pakistani context. The study would be significant because it would look at the challenges from the learners' psychological point of view which would prove helpful for teachers, course designers, learning objects (Los) designers, trainers, and learners.

\section{Purpose of Study}

The purpose of this study is to examine the relationships between psychological factors (cognitive flexibility, need for closure, and procrastination) and online self-directed learning in Pakistan. Technical challenges of online learning have been reported in Pakistan (Qureshi et al., 2012; Hussain, 2007; Hussain, 2012; Iqbal \&Ahmad, 2010; Jawaid, et al., 2013; Khan \& Jumani, 2012; Sherazi \& Ikram, 2001; Noreen \& Hafeez (2016).Going beyond technical difficulties, this study examines the potential influences of students' general cognitive factors, need for closure, cognitive flexibility and procrastination on their online learning. 


\section{Perspectives and Theoretical Framework of Psychological Factors}

Cognitive flexibility is the propensity to be nimble of mind. Students who are cognitively flexible react to new situations with a variety of ways of thinking and searching for alternative answers (Martin \& Rubin, 1995; Spiro, Collins, \& Ramchandran, 2007). This propensity would seem likely to help students' online self-directed learning. Online learners typically need to be a more independent learner. They need to take the initiative to spontaneously search for answers through alternative sources when left to their own learning (Song \& Hill, 2007).

Procrastination and need for closure are both about how time is spent. Students who typically procrastinate, avoid engaging in unpleasant tasks until the last minute. They suspend learning time and action until they have no more time left. Procrastination has predicted poor academic performance (Hoa, 2015). Academic procrastination is common amongst students, and it has relation with academic success. Academically successful students procrastinate less as compared to those who are less successful students (Kandemir,2014). Procrastination has negative impacts on the academic life of students. For example, students have low academic achievement. They are afraid of examinations. Procrastination is associated with depression and anxiety. Students who procrastinate also suffer from inferiority complex and consequently they quit studying or they opt for poor examination performance(Hussain \& Sultan, 2010).

Need for closure is a strong need to find answers or complete tasks quickly. Students will tend to quickly accept an answer (seize the answer) and resist change the answer (freeze the answer). Indeed, they are likely to stop searching for alternative answers (Kruglansi, 1990; Roets \&Van Heil, 2011).Kossowska, Jaśko, Bar-Tal, \& Szastok (2012) studied the relationships among need for closure (NFC) and schematic information processing in younger and older adults and they found that increased NFC to be associated with less schematic processing. Similarly, Rosman, Mayer, Peter, and Krampen (2016) found that need for closure effects epistemic instruction. DeBacker and Crowson (2009) also posit that need for closure has implication for teaching and learning.

In the United States of America (USA) previous research has found significant relationships between online self-directed learning and students' cognitive flexibility, procrastination, and need for closure (Authors, 2018). The more cognitive flexibility students have, the better they are in online discussion, comprehension, and stress management. The more procrastination habits students have, the less successful they are in time management, assignment completion, and comprehension. The stronger students' need for closure is, the least successful they are in stress management and time management.

Pakistan has introduced e-learning in higher education and are gradually developing a system for e-learning in the country. Pakistan took a major step towards e-learning by establishing a full-fledged Virtual University of Pakistan in 2002 which offers all courses online through its 195 regional centers all over the country Pakistani e-learning faces technical challenges such as access to computers, electricity failure, and social isolation (Qureshi, et al., 2012). Technological issues nonetheless, students' psychological characteristics are likely to be critical for successful online learning as well, particularly when students are immersed in a self-directed environment. Hence in the study being reported, Pakistani students completed measures of online self-directed learning, cognitive flexibility, procrastination, and need for closure. 


\section{Method}

\section{Participants}

Data were collected from graduate and undergraduate students of the Federal Virtual University Pakistan. All the participants were taking all the courses online in the spring semester 2019. There were 119 (74.8\%) male students and 40 (25.2\%) female students. Age of the participants ranged between21-24 years. The participants had a variety of mother tongues but all of them could speak and understand Urdu and English. The majority of the participants were either studying in semester $4(39 \%)$ and semester $3(35 \%), 6 \%$ students were doing masters. There were students from different disciplines, majority of them were from Business Administration (17\%), Computer Science (37\%), and English (7\%).

\section{Instruments}

Online Self-Directed Learning (OSDL) was assessed with a measure developed by Khiat (2015). This 40-item measure consists of statement such as, "I find excuses for not studying [in my online classes]." And "I love attending [online] seminars." Cronbach alpha has been reported as .80. Scores from this measure have predicted students' grade point average (Khiat, 2017).

Cognitive flexibility (CF) was assessed with a measure developed by Martin and Rubin (1995). This 12-item measure consists of statements such as, "I can communicate an idea in many different ways." And "I have many possible ways of behaving in any given situation." Cronbach alpha has been reported as .80. Scores from this measure have predicted USA students' online selfdirected learning (Authors, 2018).

Need for closure (NFC) was assessed with a measure developed by Kruglanski, Atash, DeGrada, Mennetti, \& Peirro, (2013). This 7-item measure consists of statements such as, "I dislike unpredictable situations." And, "I would rather make a decision quickly rather than sleep on it." Cronbach alpha has been reported as .87. Scores from this measure have predicted USA students' online self-directed learning (Authors, 2018).

Avoid Procrastination (AP) (in daily life) was assessed with an instrument developed by Tuckman (1991). This 7-item measure consists of statements such as, "I postpone starting on things I don't like" (reverse scored). And "I manage to find an excuse for not doing something" (reverse scored). Cronbach alpha has been reported as .90. Scores from this instrument predict poor academic self-efficacy and low self-esteem scores (Ozer, Sackes, \& Tuckman, 2013).

\section{Adapting Instruments for Pakistani Students}

These tools were developed and used in USA. As this is a comparatively different context, it was necessary to adapt the questionnaires. First, some terms such as, freshmen, sophomore and so on were changed to semester1, semester 2, etc. which is customary in Pakistan. Similarly, the original questionnaire used many colloquial terms. They were changed into common terms so that the students may understand them easily, for instance, 'put time into' was changed into 'give time', 'put off until tomorrow' into 'delaying things' etc. Then, the questionnaire was pilot tested on a few students of Virtual University. It was found that still there were some difficulties and ambiguities.

All of items were again reviewed and it was decided that if the questionnaire is translated into Urdu (National Language of Pakistan) it would make it more comprehensible to the respondents. Hence, the questionnaires were translated into Urdu. First, the researcher from Pakistan translated them into Urdu. Subsequently, the scales were shown to two professors who were fluent in Urdu and English. They suggested changes which were incorporated accordingly. 
After that the scales were pilot tested again, this time it was quite easy for the respondents to respond to the items in the questionnaires.

In order to ensure that students understood the questionnaire and that they were cooperating, additional item was inserted among the items. The cooperative question was, "If you have answered questions honestly mark 'Strongly Agree' (6)..'

\section{Psychometrics}

Since these measures were being used in a new culture, a series of exploratory factor analyses (EFA) were conducted for each measure to identify items that were effective for this sample. Varimax rotation was used to maximize uniqueness to each measure. The first EFA for each measure used the value of 1 as the cutoff. When this did not yield comprehensible factors, the items with low loadings were removed and EFA was conducted with remaining items. Once factor loadings were .40 or higher and factors generated had plausible meanings, scores were generated and tested with Cronbach alphas. Descriptive statistics and Cronbach alphas are shown in Table 1.

Table 1 Descriptive Statistics and Cronbach Alphas of Key Variables

\begin{tabular}{lccc}
\hline Factor Name & Mean & $S D$ & Cronbach Alpha \\
\hline Cognitive Flexibility & 4.00 & 1.04 & .72 \\
Avoid Procrastination: & 4.12 & 1.02 & .66 \\
Need for Closure & 3.71 & 1.28 & .72 \\
Effective OSDL & 4.04 & .84 & .78 \\
Ineffective OSDL & 3.23 & .95 & .83 \\
\hline
\end{tabular}

\section{Data collection Procedure}

The study began with the permission for carrying out study in online classes at Federal Virtual University of Pakistan, based in Lahore, one of the mega cities in Pakistan. The university has study centers all over Pakistan. The centers guide the students in admission and examination.

The Pakistani researcher in this study also contacted the managers of the centers for conducting the study. He visited the centers and briefed the managers on the study. He also collected data from the available students on the day of visit and handed over the questionnaires for the remaining students. The researcher visited the centers for collection of the questioners and/or requested the managers to send via registered mail.

Once the questionnaires were back from the centers, the researchers perused the questionnaires for compliance. Those questionnaires were included, if all items were answered, and the cooperative question was answered correctly. 


\section{Results}

Zero order correlations among key variables are shown in Table 2.

Table 2 Zero Order Correlations among Key Variables

\begin{tabular}{lllll}
\hline & EOSDL & IOSF & CF & AP \\
\hline IOSDL & -.08 & & & \\
CF & .55 & .06 & & \\
AP & .58 & -.16 & .56 & .26 \\
NFC & .33 & .10 & .07 & \\
\hline
\end{tabular}

The following factors were generated. Cognitive Flexibility (CF) with emphasis on embracing new situations with 5 items (e.g., "I can communicate an idea in many different ways."); Avoid Procrastination (AP) as a daily habit in life with 5 items (e.g., "I put the necessary time into even boring tasks, like studying."); Need for Closure (NFC) quick answers with a sense of irritation if a solution is not found quickly with 3 items (e.g., "I would become impatient and irritated if I would not find a solution to a problem immediately."); Effective Online Self-Directed Learning (EOSDL) with an emphasis of good comprehension, confidence in learning, and enjoying learning online with 12 items (e.g., "I reflect on what I have learned during online presentations." and "I set targets to achieve for assignments and examinations for each course." ; and Ineffective Online Self-Directed Learning (IOSDL) with emphasis on poor comprehension and a feeling of insecurity with online classes with 11 items (e.g., "I do not understand what my instructor says during online presentations." and "I feel intimidated whenever I use the internet.". Interitem reliability was acceptable for all these factors.

\section{Predicting Online Self-Directed Learning}

Step-wise multiple regression was used to determine the significant predictors on EOSDL and IOSDL. Psychological factors (CF, AP,NFC) and basic demographics (age, gender, educational level, number of online classes taken) competed for entry. The variable accounting for the most variance at each step entered the equation. Variables entered until there were no more significant variables at the .05 level.

Table 3 shows that three psychological factors predicted EOSD accounting for a total of $47 \%$ of the variance: AP (positive $b$-weight), CF (positive $b$-weight), and NFC (negative $b$ weight). The more students avoid procrastination in general, the more students embraced cognitive flexibility, and the less they impulsively sought quick solutions, the more likely they reported selfdirected learning that was confident, effective, and joyful. 
Table 3 A Summary of Regression Results Predicting Online Self-Directed Learning (OSDL)

\begin{tabular}{llllll}
\hline Criterion Variable & Predictor Variable & $\mathrm{b}$ weight & $R^{2}$ change & $F$ & $p$ change \\
& & & & change & \\
\hline Effective OSDL & Avoid Procrastination & .48 & .38 & 63.07 & .001 \\
& Cognitive Flexibility & .29 & .08 & 17.28 & .001 \\
& Need for Closure & -.18 & .07 & 15.62 & .001 \\
Ineffective OSDL & Age & -.05 & .06 & 7.43 & .007 \\
& Need for Closure & .15 & .04 & 5.72 & .02 \\
& Avoid Procrastination & -.16 & .03 & 4.22 & .04 \\
& Cognitive Flexibility & .20 & .03 & 4.94 & .03 \\
\hline
\end{tabular}

Four psychological factors predicted (IOSD) accounting for a total of $16 \%$ of the variance; age (negative $b$-weight), NFC (positive $b$-weight), AP (negative $b$-eight) and CF (positive $b$ weight).Students who were younger, had a need for quick answers, procrastinate in general, and who indicated cognitive flexibility, were more likely to report self-directed learning that was insecure, had poor comprehension, and a sense of dread. Table 3 shows the key components of each regression analysis.

\section{Discussion and Conclusion}

This study investigates potential psychological contributors to online self-directed learning in a country that is in the early stages of e-learning. That fact that links between these variables are evident, indicates the generalizability of past research. It also suggests that students' psychological propensities in daily life carry over to the digital world.

Having high quality instruction online, notwithstanding, cognitive flexibility, avoiding procrastination, and the persistence in learning overtime appear to predict successful and joyful learning in the virtual world. Previous research in on-the-ground instruction have provided evidence that psychological factors contribute to self-directed learning in the traditional classroom. Cognitive flexibility helps students respond to problems in a variety of ways, avoiding procrastination helps students engage in spaced practice which has been shown to improve long term memory of learned material (Authors, 2018; Tuckman, 1991). Belief in quick learning or a need for quick closure has consistently been linked to poor comprehension and poor meta comprehension (Kloosterman \& Stage, 1992; Kruglansi, 1990; Roets \& Heil, 2011). These results suggest that high quality instructional techniques may be less effective, if students taking the virtual courses do not have the cognitive tools to engage in high quality studying.

Prior research investigating student drop-out rate in MOOCs programs has been attributed to technical difficulties such as digital divide, low bandwidth, and computer viruses(Sultan and Al-Lail,2015).The results of this research suggest that if technical issues were solved, there remains psychological issues to address as well. 
One possible implication for preparing online classes is that instructors may want to assess students' cognitive propensities before classes begin. Pre-semester workshops could provide instruction on the benefits of cognitive flexibility, spaced-practice learning, and persistence over time to learn new material.

Instructors may want to add more (brief) online quizzes throughout the semester. This could serve as an impetus for students to work consistently throughout the course. It also provides feedback to students and instructors on students' progress.

This study sets the foundation for future investigations of online self-directed learning. A number of questions could be addressed. For example, how do students' psychological propensities at the onset of taking a MOOC course relate to students' retention rate, student success, and student likelihood to take more online courses? Will students' online self-directed learning improve if they continue to take MOOC courses? Can providing students with short workshops on psychological propensities before they take online courses increase the likelihood of course completion and course success?

\section{References}

Abidi, S. H., Pasha, A., \& Ali, S. (2016). Participant Experience of the First Massive Open Online Course (MOOC) from Pakistan. Current Issues in Emerging eLearning, 3(1), 11.

Abidi, S. H., Pasha, A., Moran, G., \& Ali, S. (2017). A roadmap for offering MOOC from an LMIC institution. Learning, Media and Technology, 42(4), 500-505.

Albelbisi, N. A., \& Yusop, F. D. (2019). Factors Influencing Learners' Self-Regulated Learning Skills in a Massive Open Online Course (MOOC) Environment. Turkish Online Journal of Distance Education, 20(3), 1-16.

Allama Iqbal Open University Islamabad (2019). AIOU Library Network. Retrieved from http://library.aiou.edu.pk/ on 28/4/2019

COMSAT University Virtual Campus Islamabad, 2019). Quality Education at Your Door Step. Retrieved from https://vcomsats.edu.pk/on 24/4/2019

Concannon, F., Flynn, A., \& Campbell, M. (2005). What campus-based students think about the quality and benefits of e-learning? British journal of educational technology, 36(3), 501512.

DeBacker, T. K., \& Crowson, H. M. (2009). The influence of need for closure on learning and teaching. Educational Psychology Review, 21(4), 303-323.

Farid, S., Ahmad, R., Niaz, I. A., Arif, M., Shamshirband, S., \& Khattak, M. D. (2015). Identification and prioritization of critical issues for the promotion of e-learning in Pakistan. Computers in Human Behavior, 51, 161-171.

Higher Education Commission of Pakistan (2019) Faculty Development Program. Retrievedfrom www.hec.edu.pk on 25/3/2019

Hoa, L. M. (2015). What predicts your grade better? (Correlates of academic performance, selfefficacy and explanatory style with academic performance. Weber Psychiatry \& Psychology, 1, 1-18. http://www.weberpub.ort/wpp.htm

Hussain, I. (2007) A Study of Student's attitude towards Virtual Education in Pakistan. Turkish Online Journal of Distance Education-TOJDE 8(2). pp. 69-79. 
Hussain, I. (2012). Study on Instructional Paradigms of Virtual Education in Pakistan: A Learners' Perspective. Turkish Online Journal of Educational Technology-TOJET, 11(2), 178-186.

Hussain, I., \& Sultan, S. (2010). Analysis of procrastination among university students. Procedia-Social and Behavioral Sciences, 5, 1897-1904.

Iqbal, M. J., \& Ahmad, M. (2010). Enhancing quality of education through e-learning: the case study of Allama Iqbal Open University. Turkish Online Journal of Distance Education, 11(1), 84-97.

Iqbal, M. J., and Mumtaz, A. (2010) Enhancing Quality of Education through E-Learning: The Case Study of Allama Iqbal OpenUniversity. Turkish Online Journal of Distance Education-TOJDE 11(1). pp. 84-97. ISSRA. (2016). A Road Map to Vision 2025. Islamabad: National Defense University.

Jawaid, M., Kamran H., Khan M. K., and Khalique A. (2013) Computer Usage and Attitudes towards E-Learning among first-Year Medical Students in Karachi, Pakistan. KMUJ 5(1). pp. 13-17.

Jumani, N. B., \& Khan, S. B. (2009). Higher education through distance learning in Pakistan. Asian Journal of Distance Education, 7(1), 5-13.

Kandemir, M. (2014). Reasons of academic procrastination: Self-regulation, academic selfefficacy, life satisfaction and demographics variables. Procedia-Social and Behavioral Sciences, 152, 188-193.

Khan, A. (2007). The Education System and Prospects for e-learning in Pakistan. End-to-End eLearning, Stockholm College, Stockholm.

Khan, S. B., \& Jumani, N. B. (2012). E-Learning versus traditional learning in Pakistan. Asian Journal of Distance Education, 10(1), 28-34.

Khiat, H. (2015). Measuring self-directed learning: A diagnostic tool for adult learners. Journal of University Teaching and Learning Practice, 12, 1-12. http://ro.uow.edu.au/jutlp/vol12/iss2/2

Khiat, H.(2017)Academic performance and the practice of self-directed learning: The adult student perspective,Journal of Further and Higher Education,41:1,44-59,DOI: $\underline{10.1080 / 0309877 X .2015 .1062849}$

Kloosterman, P., \& Stage, F. K. (1992). Measuring beliefs about mathematical problem solving. School Science and Mathematics, 92, 109-115. DOI: 10.1111/j.1949-594. 1992.tb12154.x

Kossowska, M., Jaśko, K., Bar-Tal, Y., \& Szastok, M. (2012). The relationship between need for closure and memory for schema-related information among younger and older adults. Aging, Neuropsychology, and cognition, 19(1-2), 283-300.

Kruglanski, A. W. (1990). Motivations for judging and knowing: Implications of Learning in online environments. Journal of Interactive Online Learning, 2, 333-368.

Kruglanski, A. W., Atash, M. N., De Grada, E., Mannetti, L., \& Pierro, A. (2013). Need For Closure Scale (NFC). Measurement Instrument Database for Social Science. Retrieved from www.midss.ie. 
Martin, M. M., \& Rubin, R. B. (1995). A new measure of cognitive flexibility. Psychological Reports, 76, 623-626.

Ministry of Information Technology and Telecom (2019). Digital Skills Retrieved from https://www.digiskills.pk/WhatsDigiSkills.aspx on 27/4/2019

Noreen, S., \& Hafeez, A. (2016) Challenges of Digital Learning for Distance Universities of Pakistan. Gomal University Journal of Research, Special Issue II, ISSN: 1019-8180

Pakistan Ministry of Information, Technology and Telecom. Digiskills Program. Retrieved fromhttps://digiskills.pk/ on 25/4/2019

Piscitelli, A. (2015). ¿Está cambiando la tecnologia la Universidad? Humanidades digitales y nuevo normal educativo [Is the University changing technology? Digital humanities and new normal education]. Telos, 101,13-22.

Qureshi, I. A., Ilyas, K., Yasmin, R., \& Whitty, M. (2012). Challenges of implementing e-learning in a Pakistani university. Knowledge Management \& E-Learning, 4(3), 310.

Ozer, B. U., Sackes, M., \& Tuckman, B. W. (2013). Psychometric properties of the Tuckman Procrastination Scale in Turkish sample. Psychological Reports, 113, 874-884. Doi 10.2466/03.20.PRO.113x28z7

Roets, A., \& Van Hiel, A. (2011). Item selection and validation of a brief, 15-item version of the Need for Closure Scale. Personality and Individual Differences, 50(1), 90-94.

Rosman, T., Mayer, A. K., Peter, J., \& Krampen, G. (2016). Need for cognitive closure may impede the effectiveness of epistemic belief instruction. Learning and Individual Differences, 49, 406-413.s

Sawahel, W. (2013). Africa is most dynamic e-learning market on the planet university world news, 25 January 2013 Issue No: 256. Available from http://www.universityworldnews.com/article.php?story=20130125105755921

Shah, H. J., \& Attiq, S. (2017). Role of E-Learning in National Development. Journal of Managerial Sciences, 11(1).

Sherazi, S. N., \& Ikram, M. J. (2001). A Hybrid distance education model for Pakistan. The Electronic Journal of e-Learning, 3, 1(68).

Song, L., \& Hill, J. R. (2007). A conceptual model for understanding self-directed learning in online environments. Journal of Interactive Online Learning, 6(1), 27-42.

Spiro, R., Collins, B. P., \& Ramchandran, A. R. (2007). Modes of openness and Flexibility in cognitive flexibility hypertext learning environments. In B. Khan (Ed.), Flexible learning (pp. 18 - 25). Englewood Cliffs, NJ: Educational Technology.

Sultan, N., \& Al-Lail, H. J. (Eds.). (2015). Creative Learning and MOOCs: Harnessing the Technology for a 21 st Century Education. Cambridge Scholars Publishing.

Tuckman, B. W. (1991). The development and concurrent validity of the Procrastination Scale. Educational and Psychological Measurement, 51, 473-480.

Federal Virtual University of Pakistan. Virtual Campuses. Retrieved from https://www.vu.edu.pk/ 